\title{
Repensando os estudos de recepção: dois mapas para orientar o debate
}

\author{
Nilda Jacks
}

Universidade Federal do Rio Grande do Sul

E-mail: jacks@ufrgs.br 
Nilda Jacks

\section{Resumo}

Este texto reflete sobre mapas teóricometodológicos que orientaram o debate nos últimos anos nas pesquisas sobre meios de comunicação e cultura. Inicialmente, reflete sobre perspectivas teóricas que pautaram pesquisas sobre os estudos de recepção, discutindo categorias, proposições e apropriações da obra de Martín-Barbero, apresentando, na sequência, dados sobre o corpus analisado com o objetivo de cotejar o desenvolvimento em curso para as pesquisas da área.

Palavras-chave: meios de comunicação; estudos de recepção; cultura; MartínBarbero.
Abstract

This essay reflects upon the theoretical and methodological maps that have guided the recent research debates in the field of mass media and cultural studies. It starts with a discussion of the theoretical perspectives that framed research on reception, problematizing its categories, propositions and appropriations of the work of MartinBarbero; it then presents data on the works analyzed here, in order to outline the directions of the research developed in this area.

Keywords: mass media; reception studies; culture; Martín-Barbero.

ILHA

volume 10 - número 2 
$\mathrm{E}$ ste texto está calcado em várias publicações (Jacks et al., 2005, 2006, 2007) que frutificaram de uma pesquisa sobre os estudos de recepção desenvolvidos nos programas de pós-graduação em Comunicação na década de 1990 (teses e dissertações). O "mapa número 1", a seguir, diz respeito à discussão teórica que ambientou a referida pesquisa e o "mapa número 2", na sequência, traz dados sobre o corpus analisado.

\section{a) Mapa número 1}

Trata-se da defesa feita no início dos anos 2000 por Jesús MartínBarbero, um dos grandes mentores do desenvolvimento dos estudos de recepção na América Latina, da urgência de retomar a preocupação com os meios de comunicação no âmbito dos estudos de recepção, diante das transformações tecnológicas ocorridas nas últimas décadas. Embora seus ensinamentos nunca tenham prescindido do lugar dos meios na análise dos processos de recepção, no prefácio da edição comemorativa dos dez anos da publicação de De los medios a las mediaciones (2003) ele o faz de maneira inequívoca.

Para tal, diz que é preciso considerar que os meios, hoje, têm um papel diferente e, em boa medida, inverso ao que tiveram no tempo da conformação das identidades nacionais, como estratégia política dos Estados-nação em formação, especialmente na América Latina. Atualmente, os meios de comunicação e as tecnologias de informação minimizam o contexto nacional, ao mesmo tempo que configuram comunidades hermenêuticas internacionais, redimensionando, portanto, as identidades, pois eles simultaneamen-

ILHA

volume 10 - número 2 
te globalizam e fragmentam, além de, paradoxalmente, deslocarem e revitalizarem o local.

Explica que entender o lugar estratégico da comunicação na configuração de novos modelos de sociedade é uma maneira de ultrapassar a noção hegemônica de que ela é regida apenas pelo mercado. Embora admita que resida nesse âmbito parte essencial de sua atuação, nomeada por ele de "hegemonia comunicacional do mercado na sociedade", o autor aponta que a maneira de enfrentá-la é pela "batalha política", possibilitada pela cultura e pela comunicação.

As mudanças históricas - que poderíamos chamar de mediações exteriores à comunicação - e a introdução de novas tecnologias - interiores ao campo - fazem mover as teorias, e, nesse caso, MartínBarbero está atento tanto aos meios que operam pontualmente quanto aos que estão operando transversalmente, como é o caso da internet.

Na esfera da política, por exemplo, os meios passaram de meros intermediários à cena principal na configuração dos sentidos do discurso e da ação, na fiscalização dos governos e das instituições estatais e na facilitação do diálogo entre Estado e sociedade civil, mesmo que disfarçando alguns interesses. De acordo com o autor, diante dessas novas atuações, os meios abrem-se à interlocução com organizações nacionais e locais, como as de tipo cívico e ecológico, além de promoverem outro tipo de relacionamento com a audiência, passando de uma cultura de massa a uma cultura segmentada. Contrariando certas tendências teóricas, os meios entenderam que a audiência ou os públicos não são entes indiferenciados ou passivos, mas têm uma forte diversidade de gostos e modos de consumir. Isso obriga a pesquisa a revisar a ótica sobre a identificação imediata da cultura midiática com o processo de homogeneização cultural e colocar a comunicação como "movimiento que atraviesa y desloca a la cultura. Pues el lugar de la cultura en la sociedad cambia cuando la mediación tecnológica de la comunicación deja de ser meramente instrumental para convertirse en estructural" (Martín-Barbero, 2002a, p. 225).

É nesse cenário que Martín-Barbero propõe um novo mapa que dê conta da complexidade existente nas relações constitutivas da 
comunicação na cultura, "pues los medios han pasado a constituir un espacio clave de condensación e intersección de la producción y el consumo cultural, al mismo tiempo que catalizan hoy algunas de las más intensas redes de poder" (2002a, p. 226). E é nessa tensão, entre as inescapáveis lógicas do mercado e das tecnologias de comunicação/informação e as mediações histórico-culturais, que o pensamento crítico vislumbra uma possibilidade de refletir a relação da cultura com os meios de comunicação.

São configuradoras dessa tensão e compõem as mediações comunicativas da cultura a socialidade, a ritualidade, a tecnicidade e a institucionalidade dispostas entre dois eixos: um diacrônico, de longo alcance, tensionando as matrizes culturais e os formatos industriais; e um sincrônico, constituído entre as lógicas de produção em sua relação com as competências de recepção e consumo. ${ }^{1}$

As três primeiras mediações já estavam presentes nas reflexões iniciais de Martín-Barbero (1990) sobre o tema e logo foram apontadas por Orozco Gómez (1996) como desdobramento da reflexão apresentada em De los medios a las mediaciones.

Por outro lado, a institucionalidade, mediação ausente até então, surge para dar conta de maneira mais concreta e específica do âmbito dos meios, ou seja, dos discursos públicos, carregados de interesses e poderes contraditórios, mas que tendem à homogeneidade.

Há diferentes regimes de institucionalidade, e é ela que faz a mediação entre as lógicas de produção e as matrizes culturais, sendo o cenário, portanto, que constrói a relação mais próxima entre produção e recepção. Essa mediação, obviamente, é transformada por ambos os contextos - o sincrônico das lógicas de produção e o diacrônico das matrizes culturais -, através do processo histórico-cultural.

É pela institucionalidade que podem ser pensadas duas ordens contrapostas: o regime estatal, que concebe os meios como serviço público, e o regime de mercado, que converte a liberdade de expressão em comércio. Ambos atuam simultaneamente na configuração do espaço público contemporâneo a partir da priorização de valores quase sempre antagônicos. Nas palavras de Martín-Barbero (2002a, p. 230), “al mediar en la constituición de lo público y en el

\section{ILHA}

volume 10 - número 2 
reconocimiento cultural, la trama institucional de la comunicación hace parte del lazo ciudadano". Para o autor, a institucionalidade afeta a regulação dos discursos tanto do Estado quanto dos cidadãos. No primeiro caso, isso ocorre em nome da busca da estabilidade para a ordem constituída e, no segundo, para defender seus interesses e fazer-se reconhecer, reconstruindo o social permanentemente.

Do ponto de vista da institucionalidade, a comunicação é uma questão de meios, de produção de discursos públicos, cuja hegemonia encontra-se paradoxalmente do lado dos interesses privados. Do ponto de vista da socialidade, é uma questão de fins, da constituição do sentido, do fazer-se e desfazer-se da sociedade.

A socialidade (ou sociabilidade), portanto, tanto quanto a institucionalidade, apresenta diferentes regimes, isto é, depende da trama que se estabelece em cada cotidiano, o qual, ao mesmo tempo, ancora a práxis comunicativa e é o resultado dos modos e usos coletivos da comunicação e das relações de poder (Martín-Barbero, 2003), ou seja, ela medeia o âmbito que se estabelece entre as matrizes culturais e as competências de recepção/consumo, figurando como um amálgama que vincula a tradição cultural com o modo de os receptores relacionarem-se com a cultura massiva. Ela tece, através das práticas cotidianas, o eixo diacrônico das matrizes culturais com o sincrônico das práticas de recepção e consumo, engendrando uma urdidura para a produção de sentido.

Essa categoria permite analisar o cenário em que os receptores atuam e interatuam, em que exercem suas práticas e seu habitus, em que a subjetividade e as identidades constroem-se e reconstroem-se com o fim de entender o que passa no mundo da recepção e do consumo, ou seja, no mundo dos atores sociais e suas vinculações com o mundo social. Segundo Orozco Gómez (1996, p. 93), a socialidade "constituye un conjunto de interacciones estructuradas por la audiencia en su lucha por apropiarse creativamente del orden social [...], del orden propuesto por la TV".

Sinaliza Martín-Barbero (2002a, p. 227) que a importância dessa mediação para analisar as práticas dos receptores "no significa el desconocimiento de la razón codificante o la fuerza del habitus sino 
la apertura a otros modos de inteligibilidad 'contenidos' en la apropiación cotidiana de la existencia y su capacidad de hacer estallar la unificación hegemónica del sentido".

Por isso, apesar de importante, não basta somente o conhecimento do contexto cotidiano para entender os processos de recepção e consumo, mas todas as instâncias e lógicas da produção, assim como as mais amplas características da cultura em questão, ou seja, as matrizes culturais.

Como pode ser observado no mapa barberiano (Martín-Barbero, 2003), são as matrizes culturais (eixo diacrônico) que angulam as lógicas de produção e as competências de recepção, ambas (eixo sincrônico) tendo na relação com as matrizes a institucionalidade e a socialidade, respectivamente, como configuradoras desses processos de produção e recepção.

Quanto à ritualidade, ela aparece no mapa mediando os formatos industriais e as competências de recepção/consumo, sendo responsável pelos nexos simbólicos que configuram a relação da audiência com os meios, ou seja, o processo de comunicação. Por ela é mobilizada a memória dos receptores - seus ritmos e formas, os cenários de interação e repetição -, constituindo uma gramática de ação nas relações que estabelece com os formatos industriais (discursos, gêneros, programas e grades de programação etc.), utilizados pelos meios. Assim, a ritualidade regula a interação entre os espaços e tempos da vida cotidiana e os espaços e tempos concebidos pelos meios, através das práticas de recepção constituídas pelo olhar, pela escuta e pela leitura. Segundo Martín-Barbero (2003), por parte dos meios, isso implica uma capacidade para colocar regras nos jogos entre significação e situação, alertando, entretanto, que uma coisa é a significação da mensagem e outra é o sentido que ela adquire quando o receptor apropria-se dela. É através dessa categoria que se pode estudar os diferentes usos sociais dos meios a que tanto alude o autor a respeito da necessidade de entender as mediações que configuram e reconfiguram os processos de recepção. Para Orozco Gómez (1996, p. 93), "la ritualidad abarca ciertas formas de acción que no solo se adoptan rutinariamente, sino que simplemente se

ILHA

volume 10 - número 2 
Nilda Jacks

repiten por los miembros de la audiencia". Entram aqui os diferentes modos de leitura/apropriação dos meios e das mensagens, baseados em hábitos familiares e de classe, níveis e qualidade da educação formal, experiências geracionais, memórias étnicas, entre outros elementos que dão forma social ao gosto.

A ritualidade categoriza, portanto, a forma com que se concretiza a comunicação (ou o intercâmbio), garantida pelas regularidades e pelos ritmos que reconstroem permanentemente os nexos simbólicos, sendo “a la vez repetición y innovación, anclaje en la memoria y horizonte abierto", conforme expõe Martín-Barbero (2002a, p. 228). Essa mediação possibilita o conhecimento da gramaticalidade que opera na expressão e no compartilhamento do sentido.

Como foi visto até aqui, ritualidade e socialidade operam simultaneamente na configuração das competências de recepção e consumo, ou seja, são as categorias que as conectam aos formatos industriais e às matrizes culturais, não significando, com isso, que as demais não sejam relevantes para entender o processo.

A tecnicidade, por exemplo, que é a categoria que medeia os formatos industriais e as lógicas de produção, segundo Martín-Barbero (2003, p. xix), é "menos asunto de aparatos que de operadores perceptivos y destrezas discursivas", ou seja, ultrapassa em muito o âmbito da produção. O autor alerta, inclusive, que não se confunda comunicação com técnicas e meios, indicando que a tecnicidade opera como um sensorium que conecta as inovações com os modos de percepção e experiência social, conforme já apontava Walter Benjamin ao tratar da obra de arte na era da reprodutibilidade técnica.

Para Martín-Barbero (2002a), a técnica extrapola a ordem instrumental e sedimenta os saberes e a constituição das práticas, por isso a tecnicidade como categoria é a responsável por tornar visível todas as formas de inovação que permeiam o âmbito da produção, as quais indubitavelmente irão afetar seus discursos e formas - sua gramática -, além dos modos de perceber e sentir dos receptores. O autor aponta, ainda, que a técnica opera como um organizador perceptivo que, através das práticas, articula a transformação material às inovações discursivas, ou seja, "las materialidades del discurso

\section{ILHA}

volume 10 - número 2 
remiten a la constitución - a lo largo de los procesos históricos - de gramáticas discursivas originadas en formatos de sedimentación de saberes narrativos, hábitos y técnicas expresivas" (Martín-Barbero, 2002a, p. 231). Nesse sentido, Orozco Gómez (1996, p. 93) considera que "cada medio y especialmente cada género programático tiene una tecnicidad específica, que media la percepción del sujeto al organizar su negociación de significados con los contenidos".

Entendendo essa mediação como configuradora de fenômenos que extrapolam os meios, Martín-Barbero (2002a) afirma que a técnica, mais do que aparelhos, é uma questão de formato de novas práticas; mais do que destrezas, é linguagem, sendo a mediação da tecnicidade a que aponta para o novo estatuto social da técnica, para a rediscussão do sentido do discurso e da práxis política, para o novo estatuto da cultura e para os avatares da estética.

Assim, comunicação, cultura e política - tríade que o autor identifica como necessária para tematizar o novo contexto teóricoempírico da contemporaneidade - são abarcadas no mapa que acabamos de comentar pelos elementos constitutivos dessa relação - as matrizes culturais e os formatos industriais (eixo diacrônico), as lógicas de produção e as competências de recepção/consumo (eixo sincrônico -, mediados pelas categorias comentadas acima: socialidade, ritualidade, institucionalidade e tecnicidade.

Aos elementos desses eixos e às categorias que os medeiam Martín-Barbero denomina mediações comunicativas da cultura, as quais voltam a pôr em relevo os meios de comunicação na análise dos processos comunicativos, ainda assim sem concebê-los como os únicos e grandes mediadores entre as pessoas e o mundo. A passagem do modelo das mediações culturais da comunicação para o das mediações comunicativas da cultura recoloca a necessidade formal de trabalhar os meios e todos os recursos que os rodeiam de forma mais enfática para entender a cultura contemporânea, sem deixar, entretanto, de considerar todos os elementos da estrutura sociocultural que configuram a relação das pessoas com os meios de comunicação.

Assim, motivos teóricos, políticos e empíricos levaram o autor a reconsiderar seus aportes iniciais, os quais tiveram uma repercussão

ILHA

volume 10 - número 2 
Nilda Jacks

positiva no mundo acadêmico latino-americano e definiram os rumos das pesquisas brasileiras nos anos 1990, especialmente no que tange aos estudos de recepção.

\section{b) Mapa número 2}

Trata-se de alguns resultados da análise detalhada da produção brasileira desenvolvida na década de 1990 (Jacks et al., 2005, 2006 e 2007) com o objetivo de cotejar o desenvolvimento em curso (2000 em diante). Destaca-se a ênfase em uma maneira mais complexa de problematizar as relações entre meios e audiências, sem abrir mão dos avanços e das conquistas realizados em mais de uma década de exploração empírica e discussão teórica com base nos ensinamentos do autor do "mapa número 1", ou seja, ao apresentarmos a discussão atualizada por Martín-Barbero, consideramos que ela aponta para a superação das debilidades encontradas na produção da década de 1990, que, de maneira geral, desconsiderou as determinações engendradas, por exemplo, pelos meios e pelas mensagens, pautadas que estavam pelos ditames teóricos da época.

Não queremos afirmar com isso que reconhecemos somente essa possibilidade para estudar as práticas de recepção, o que seria reduzir demasiadamente a compreensão desse fenômeno. Estamos apenas seguindo a tendência encontrada na análise da produção da década de 1990 e apontando para as soluções possíveis dentro da mesma perspectiva teórica, que, como pudemos verificar acima, ainda não se esgotou.

Problemas metodológicos constituem o ponto crítico da maioria dos trabalhos analisados, aspecto, segundo nossa avaliação, por onde deve começar o debate para reinstaurar a capacidade dos estudos de recepção para entender de forma mais complexa os processos de comunicação na contemporaneidade. Um dos sinais disso é que os capítulos metodológicos estão ausentes na maioria dos trabalhos, sintoma já identificado por outros analistas (La Pastina; McAnany, 1994; Lozano; Frankenberg, 2007) e que, de certa forma, reflete a pouca importância dada pelos pesquisadores a esse tema. Sem esse

ILHA

volume 10 - número 2 
lugar conceitual-operacional, certas debilidades são previsíveis, como amostras precariamente constituídas, mal ou não apresentadas nos relatos de pesquisa, procedimentos e técnicas não problematizados à luz do objeto e do problema, às vezes beirando a repetição de uma receita. O mesmo aconteceu com os procedimentos analíticos, os quais também não foram explicitados, especialmente no que tange às falas dos receptores, que raramente mereceram uma análise mais acurada, pois, no geral, foram tomadas sem a necessária articulação com seu mundo simbólico e social, ou seja, não há processo analítico e interpretativo dos discursos produzidos pelos entrevistados, apenas a transcrição das respostas dos informantes às questões feitas pelo pesquisador.

Essas inconsistências metodológicas podem ter resultado da inobservância dos critérios de cientificidade que fundam a pesquisa contemporânea e garantem a legitimidade de seus protocolos, os quais são a verificação, a duplicação, a transparência e a falseabilidade (Appadurai, 2006), tidos por muitos analistas, inclusive, como elementos éticos da pesquisa. Segundo Appadurai (2006, p. 11), "todos estos criterios fueron elaborados con la intención de eliminar la técnica del virtuoso, la intuición aleatoria, la epifanía del generalista y otras fuentes privadas de fiabilidad".

Entretanto, embora falíveis sob o ponto de vista de um ou outro desses critérios, foram encontrados no conjunto desses trabalhos os que primam por procedimentos sistemáticos que lhes garantem qualidade acadêmica, especialmente porque buscavam conhecer fenômenos emergentes e produzir novos conhecimentos. Ressalta Appadurai (2006, p. 9), entretanto, que não se trata de qualquer conhecimento, mas daqueles que cumprem certos critérios, como o de surgir de algum entendimento claro sobre conhecimentos existentes e relevantes. ${ }^{2}$ Alguns trabalhos, porém, parecem estar de costas para a comunidade científica, pois não dialogam com os resultados obtidos pelos pares, deixando de cumprir preceitos básicos do protocolo de pesquisa: revisão da literatura, citações estratégicas e definição apropriada de conhecimentos anteriores, normalmente disciplinares (Appadurai, 2006). Ao desconsiderarem esse princípio

ILHA

volume 10 - número 2 
básico, alguns estudos propuseram objetos parecidos, chegaram a resultados similares sem estabelecer comparações, sem avançar em direção à superação de algumas lacunas, sem se remeter ao desenvolvimento do campo. Nesse sentido, a quase totalidade das teses e das dissertações analisadas desconheceu as pesquisas desenvolvidas no mercado, mesmo quando poderia partir de dados existentes, e poucos trabalhos deixaram novas hipóteses a serem exploradas pelo campo como também pelo mercado.

O que redime certas falhas desses trabalhos, entretanto, é a novidade, pois, ainda segundo Appadurai (2006), eles agregam algo interessante ao campo, como dados empíricos sobre as mediações mais importantes que configuram a relação dos receptores com os meios de comunicação, seus mecanismos de produção de sentido, suas estratégias cotidianas para sobreviverem material e simbolicamente diante do avanço da cultura urbana e midiática, entre outros achados. Se esse elementos tivessem sido retomados pelas pesquisas desenvolvidas na década, teriam alimentado a produção da área de maneira mais consistente e consequente.

Verificamos, também, que nem todos os estudos que se propunham a ser interdisciplinares alcançaram esse objetivo, pois na instância metodológica e analítica não foram implementadas as articulações necessárias. Nessas condições, portanto, certas considerações estão baseadas em indícios fracos e calcadas em construções metodológicas frágeis. No entanto, mesmo aquelas, cujas conclusões apenas reafirmam alguns dos pressupostos adotados, deixaram pistas importantes, uma vez que cada uma delas explorou empiricamente de que maneira cada particular situação medeia a relação dos públicos estudados com os meios. O pioneirismo dessa etapa pode servir de lastro para a crítica e a autocrítica, tão salutar para o desenvolvimento do conhecimento na área.

Diante das inconsistências particulares de cada trabalho e dos resultados obtidos pelo conjunto deles, devemos considerar o estágio do conhecimento apresentado por esse campo de estudos na década de 1990. Esses limites podem ser relevados e relativizados, pois as pesquisas em discussão apresentam, constroem, descrevem e ana-

ILHA

volume 10 - número 2 
lisam, e algumas interpretam, um fenômeno quase desconhecido até então, ou seja, as fragilidades encontradas são constitutivas do campo que está em construção no diálogo com as ciências sociais e humanas e reflete o conhecimento acumulado até aqui, o que implica a formação ainda deficitária de seus pesquisadores (González, 20012002). Isso está demandando um esforço de seus agentes na superação das dificuldades e na conscientização de que o próximo passo na agenda de pesquisa é o fortalecimento dos procedimentos metodológicos, mais do que simplesmente propor o enfrentamento de problemas empíricos, os quais dependem desse ajuste de contas, que passa também pelo fortalecimento da teoria.

Assim, tomando em consideração essas peculiaridades do campo, pode-se dizer que certamente houve avanços proporcionados por alguns trabalhos. Em termos teórico-metodológicos, por exemplo, a aproximação do modelo das multimediações, proposto por Guillermo Orozco Gómez, do modelo teórico desenvolvido por Jesús MartínBarbero, ${ }^{3}$ conhecido como teoria das mediaçoes, tornou operacionais alguns conceitos propostos pelo último. Essa conjugação mostrouse eficaz para o desenvolvimento de muitos estudos, auxiliando a estruturar o desenho da investigação e fornecer parâmetros para criar categorias que emergiam do próprio objeto de estudo. Por outro lado, houve algumas explorações do tratamento analítico das entrevistas, apontando para um critério mais acurado no tratamento dessa informação. Elas não devem ganhar apenas uma interpretação subjetiva do pesquisador, devem prescindir de ferramentas adequadas e consagradas em outros campos de conhecimento, como a análise do discurso ou a semiologia, que devem ser postas a serviço dos estudos de recepção. Outro avanço importante foi a preocupação com o fazer investigativo, a postura e o papel do pesquisador em campo e sua relação com os informantes, fundamental para refletir sobre a construção dos dados e sua posterior análise e interpretação.

Em termos empíricos, podemos apontar para a necessidade de dar continuidade aos estudos sobre televisão e rádio, pois, apesar de terem sido os meios mais estudados, as pesquisas sobre eles ainda são incipientes para entender as diferentes apropriações por diversos

ILHA

volume 10 - número 2 
Nilda Jacks

segmentos sociais, culturais, geracionais e regionais. Entendemos, também, que o estudo da recepção de programas específicos só se justifica quando traz luz para o entendimento de um fenômeno mais amplo ou quando pode ser remetido a outros programas ou gêneros similares. Por outro lado, é urgente prestar atenção nos demais meios e, especialmente, na conjugação deles, pois os receptores estão expostos ao seu conjunto, além do estudo da internet, lugar imprescindível para reavaliar todo o conhecimento sobre os receptores e suas práticas de recepção, visto que mais e mais usuários se conectam à rede a cada ano, sem deixar de se exporem aos meios mais tradicionais, ou ainda explorá-los através da própria web.

No que diz respeito aos públicos, todos merecem mais exploração empírica e, especialmente, maior apropriação e articulação dos dados existentes visando reproblematizar certas situações pesquisadas na busca de objetos de estudo que atualizem as dinâmicas e as práticas de recepção diante das novas demandas dos meios. Em termos da recepção infantil, por exemplo, as análises estão localizadas em programas destinados às crianças, mas isso não basta para entender esse público, uma vez que sabemos que ele está exposto a quase toda a grade da programação. Seria interessante observar, ainda, as diferentes faixas etárias encontradas nesse segmento, às quais a programação nem sempre atende completamente.

Quanto aos adolescentes, as pesquisas indicam que o rádio é o meio que mais se aproxima de seu universo por causa da música, sendo uma pista muito importante a ser seguida, o que poderá descartar certos meios que têm sido estudados e que, provavelmente, não são aqueles que os conectam efetivamente com a cultura massiva. Hoje, é imprescindível olhar de maneira sistemática a relação desse público com a internet.

Também no caso dos estudos sobre identidade cultural, o papel do rádio deveria ser levado em consideração de maneira mais sistemática, pois esse meio de comunicação estabelece um contato mais próximo com as diversas realidades locais e suas respectivas identidades, devido ao seu caráter mais segmentado. Mesmo que o fenô-

ILHA

volume 10 - número 2 
meno estudado tenha como suporte outro meio, o rádio deve ser examinado porque muitas vezes faz a mediação entre o cenário nacional e o regional. Por outro lado, o estudo das identidades como mediação não pode prescindir de uma análise consistente das diversas vozes e dos elementos que forjam as especificidades da identidade que está em questão, assim como não pode se perder de vista seu caráter histórico. Como as identidades são construções simbólicas, é preciso tratá-las segundo as clivagens que resultam desse processo, pois é possível que as apropriações realizadas pelos sujeitos identificados obedeçam a essas dimensões.

No caso das mulheres, como já foi apontado por Escosteguy (2004), há uma categorização desse segmento pelo sexo e não uma identificação como gênero, o que simplifica demasiadamente o entendimento de sua relação com os meios, não remetendo às suas identidades sociais. Há certa similaridade no trato do público rural, que tem sido normalmente tomado como aquele que vive em situação oposta ao urbano, quando cada vez é mais difícil pensar separadamente esses dois universos, devido ao encurtamento das distâncias e das novas tecnologias de comunicação.

A respeito da publicidade, apesar de os estudos empíricos terem sido desenvolvidos a partir de estratégias teórico-metodológicas que contemplam o universo cultural dos receptores, revelando a complexidade do fenômeno, especialmente em relação ao consumo e à questão da identidade, podemos recomendar algumas qualificações. Surpreende a distância da pesquisa acadêmica em relação àquela realizada no mercado, dada a tradição da pesquisa realizada pelas agências publicitárias no Brasil desde a década de 1950, quando começava também a pesquisa acadêmica em comunicação (Lopes, 2001). Além disso, apesar de contemplar adequadamente o contexto sociocultural e as motivações individuais dos receptores da publicidade, os estudos não dedicam devida atenção aos condicionamentos dos meios publicitários, à pulverização das mensagens persuasivas em múltiplos tempos e espaços do cotidiano ou mesmo às competências de leitura dos anúncios desenvolvidas pelos receptores.

ILHA

volume 10 - número 2 
Nilda Jacks

\section{Considerações finais: entrecruzando o mapeamento}

Em termos gerais, poderíamos dizer que, além de uma reflexão teórica com apropriação de outros campos mais afeitos a essas problemáticas, como a sociologia e a antropologia, por exemplo, é recomendável a realização de estudos comparativos, pois eles ajudam a "desessencializar" conceitos e percepções. Aliás, estudos comparativos são uma das estratégias que recomendamos para retomar o vigor dos estudos na área, tanto na esfera de públicos e espaços geográficos - entre regiões, entre países - quanto entre estudos realizados, ou ainda, partindo de resultados conhecidos para colocá-los à prova, em outra dimensão teórica ou em outra situação empírica. No primeiro caso, obviamente é necessária a tão estimulante pesquisa com equipes interinstitucionais e, na maioria dos casos, com equipes interdisciplinares.

Enfim, a articulação de conhecimentos adquiridos pelos pares é um passo importante para agir na esfera institucional e pesquisar com compromisso com o campo. Um exemplo dentro do corpus tratado é o caso da telenovela, analisada na dimensão do som e da imagem por dois trabalhos distintos. Que teria havido se um terceiro pesquisador tivesse articulado esses achados empíricos e lançado uma nova pergunta para o mesmo público ou para outro? A essa direção, também, vai a observação sobre o estudo de personagens como uma maneira de aproximar-se do receptor através de sua relação de identificação. Estudos comparativos entre apropriações de diferentes tipos de vilóes que vão sendo construídos pela teledramaturgia, em diferentes gêneros, poderiam render o desenvolvimento dessa chave deixada por um dos trabalhos analisados, o que com criatividade e perspicácia poderia ser estendido para outros assuntos ou objetos, como, por exemplo, entre dois estudos que se dedicaram a entender a recepção de um mesmo desenho animado por diferentes grupos de crianças.

Muitas outras pistas poderão ser seguidas a partir da análise da produção dessa década em que se firmou essa área de estudos no país, já sendo possível articulá-la com o que foi produzido de lá para

ILHA

volume 10 - número 2 
cá. Cremos que essa estratégia garantirá um desenvolvimento mais rápido e mais consistente da pesquisa na área.

O intuito da crítica aqui apresentada - para apontar os avanços e os limites, além de identificar pistas para requalificar a pesquisa brasileira na área da comunicação - não foi desconsiderar que os trabalhos produzidos na década de 1990 estiveram sob a égide da primeira proposição de Martín-Barbero - mediações culturais da comunicação -, portanto seguindo uma tendência da época, mas enfatizar que já está em circulação uma revisão de seu modelo, o qual propõe considerar as mediações comunicativas da cultura. Isso implica tomar de modo consistente a análise dos meios para entender os processos de recepção, abandonando os procedimentos mais comuns da década de 1990, que privilegiavam o cenário dos receptores em detrimento da observação de todos os elementos e agentes que compõem o processo.

\section{Referências}

APPADURAI, Arjun. La globalización y la imaginación en la investigación. Disponível em: < http://www.cholonautas.edu.pe/modulo/upload/ globalizacion\%20e\%20imaginacion.pdf > . Acesso em: 03 abr. 2006.

ESCOSTEGUY, Ana Carolina. Notas para um estado da arte sobre os estudos brasileiros de recepção nos anos 90. In: MACHADO, Juremir; LEMOS, André; SÁ, Simone (Org.). Mídia.Br. Porto Alegre: Sulina, 2004. p. 130-144.

GONZÁLEZ, Jorge. Cibercultura y políticas culturales. Gaceta, Bogotá, n. 48, enero 2001/dic. 2002. p. 116-143.

JACKS, Nilda et al. Recepção televisiva: pesquisas brasileiras da década de 1990. Global Media Journal en Español, 2005. Disponível em: < http:// gmje.mty.itesm.mx > . Acesso em: 03 abr. 2006.

. Recepção televisiva: o que dizem as pesquisas acadêmicas na década de 1990? In: DUARTE, Elizabeth Bastos; CASTRO, Maria Lília Dias (Org). Televisão: entre o mercado e a academia. Porto Alegre. Sulina, 2006. p. 85-105.

. En Brasil, conocemos poco sobre el público rural: investigaciones de recepción en el ámbito de la comunicación. In: OROZCO GÓMEZ, Guillermo (Org.). Un mundo de visiones: interacciones de las audiencias en múltiples escenarios mediaticos y virtuales. Cidade do México: ILCE, 2007. p. 357-374.

JACKS, Nilda; FRANKE, Felipe S. Recepção radiofônica: análise da produção acadêmica na década de 90. Revista da Intercom, São Paulo, v. 29, n. 1, jan./jun., 2006. p. 85-105.

ILHA

volume 10 - número 2 
Nilda Jacks

JACKS, Nilda; MENEZES, Daiane. Estudos de recepção e identidade cultural: abordagens brasileiras na década de 90. Revista Latinoamericana de Ciencias de la Comunicación, São Paulo, ano 3, n. 5, p. 164-175, 2006.

. Recepção de telenovela na década de 1990: um estado da arte da pesquisa. Revista Comunicação e Educação, ano 12, n. 2, p. 13-20, maio/ago. 2007a.

Públicos, audiências e receptores: análise das pesquisas brasileiras da década de 1990. Revista Argentina de Comunicación, Rio Cuarto, n. 2, p. 197-211, 2007b.

JACKS, Nilda; PIEDRAS, Elisa. Estudos de recepção da publicidade: explorando as pesquisas da década de 90. Revista Comunicação Mídia e Consumo, São Paulo, v. 3, n. 7, p. 113-130, 2006.

LA PASTINA, Antonio; MCANANY, Emile. Pesquisa sobre audiência de telenovelas na América Latina: revisão teórica e metodológica. Revista Brasileira de Ciências da Comunicação, São Paulo, v. 17, n. 2, p. 17-37, jun./dez. 1994.

LOPES, Maria Immacolata Vassalo. Pesquisa em Comunicação. São Paulo: Loyola, 2001.

LOZANO, José Carlos; FRANKENBERG, Lorena. Theoretical Approaches and Methodological Strategies. In: . Latin American Empirical Research on Television Audiences, 1992-2007. Paper submitted to the ICA Conference 2008, Montreal, Canadá.

MARTÍN-BARBERO, Jesús. Desafios à pesquisa em comunicação na América Latina. Boletim INTERCOM, São Paulo, n. 49/50, jul./out. 1984a. p. 23-35. . De la comunicación a la cultura: perder el objeto para ganar el proceso. Revista Signo y Pensamiento, Bogotá, v. 3, n. 5, 1984b. p. 17-24.

. De los medios a las mediaciones: comunicación, cultura y hegemonía. México: Gustavo Gili, 1987.

. De los medios a las prácticas. In: OROZCO GÓMEZ, Guillermo (Coord.). Comunicación desde las prácticas sociales. Cuadernos del PROIICOM, México, n. 1, p. 9-18, 1990.

- Ofício de cartógrafo: travesías latinoamericanas de la comunicación en la cultura. Santiago de Chile: Fondo de Cultura Económica, 2002a.

Medios y culturas en el espacio latinoamericano. Revista Iberoamericana, Berlim/Madrid, v. 2, n. 6, p. 89-106, 2002 b.

De los medios a las mediaciones: comunicación, cultura y hegemonía.

Bogotá: Convenio Andrés Bello, 2003.

ILHA

volume 10 - número 2 
. Poner este roto país a comunicar. Discurso pronunciado en el ortogamiento del Doctorado Honoris Causa por la Pontifícia Universidad Javeriana, Facultad de Comunicación y Lenguaje, PUJ, 2005.

OROZCO GÓMEZ, Guillermo. Televisión y audiencias: un enfoque cualitativo. Madrid: Ediciones de la Torre/Universidad Iberoamericana, 1996.

SAINTOUT, Florencia. Los estudios de recepción en America Latina. La Plata: Ediciones de Periodismo y Comunicación, Universidad Nacional de la Plata, 1998.

\section{Notas:}

1 Ver esquema em Martín-Barbero (2003, p. xvi).

2 O reconhecimento do novo, por sua vez, só se efetiva através de uma comunidade de avaliação, preexistente, profissional e especializada que valida institucionalmente tal conhecimento, especialmente em se tratando de teses e dissertações, como é o caso em questão.

3 Para uma crítica de Martín-Barbero sobre essa aproximação, ver Saintout (1998, p. 161).

Recebido em: 19/06/2008

Aceite em: 09/08/2008

ILHA

volume 10 - número 2 